\title{
Climate Change Associated with Neonatal Health Risks: Rwandan Nurses and Midwives' Awareness and Perceptions
}

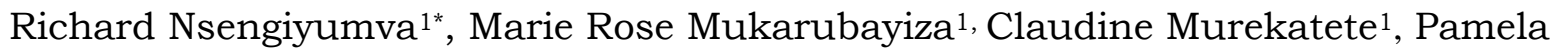 \\ Meharry $^{2}$ \\ ${ }^{1}$ School of Nursing and Midwifery, University of Rwanda, College of Medicine and Health Sciences, \\ Kigali, Rwanda \\ 2Department of Women's, Children's and Family Health Services, University of Illinois, Chicago, \\ USA
}

*Corresponding author: Richard Nsengiyumva, MScN. School of Nursing and Midwifery, College of Medicine and Health Sciences, University of Rwanda, Remera Campus, 11 KG 47, Kigali, Rwanda. Email: richnse2@gmail.com

\begin{abstract}
Background

Climate change $(\mathrm{CC})$ is a global public health problem. In Rwanda, it is estimated that $28 \%$ of neonatal death is attributable to CC, yet little is known about healthcare providers' awareness of neonatal health risks.

\section{Objective}

To assess nurses' and midwives' awareness of CC and perceptions of potential neonatal health risks associated with $\mathrm{CC}$ at selected hospitals in Rwanda.
\end{abstract}

\section{Methods}

A cross-sectional survey was performed at four selected hospitals. A random sampling technique was used to select 184 of 340 nurses and midwives working in neonatology, pediatrics, and maternity departments. Descriptive and inferential statistical tests were done.

\section{Results}

The majority of participants were females $(62.1 \%)$, nurses $(60.5 \%)$, advanced diploma holders $(55.4 \%)$. The majority (60.4\%) had low level awareness of CC, and only $2.8 \%$ obtained CC information at nursing school. The majority $(61.02 \%)$ had low perception of potential CC' related potential neonatal health risks. High education level, working in neonatology and longer working experience were found to be associated with high level awareness of CC and high perceptions of potential neonatal health risks associated with $\mathrm{CC}(\mathrm{p}<0.05)$.

\section{Conclusion}

There was a low level awareness of $\mathrm{CC}$ awareness and low perceptions of potential neonatal health risks among nurses and midwives. Offering in-service training and integrating CC' health risks in the nursing curricula could motivate climate action among Rwandan nurses and midwives.

Rwanda J Med Health Sci 2020;3(2):261-272

Keywords: Climate change, neonatal health risks, awareness, perceptions, nurses, and midwives

\section{BACKGROUND}

Climate change (CC) is recognized as one of the greatest health threats and global challenges in the $21^{\text {st }}$ century, according to the World Health Organization (WHO).[1] Currently, the rhetoric is changing from $\mathrm{CC}$ to the climate crisis, as it is causing multiple health challenges, ranging from disease outbreaks such as Coronavirus, increasing drug-resistant pathogens, and multiple humanitarian crises.[1] Globally, almost three million neonatal deaths and stillbirths are attributable to $\mathrm{CC}$ annually.[2]

One manifestation of $\mathrm{CC}$ is the increasingly severe extreme weather that causes injury, illness, and death through heat stress, air pollution and infectious diseases on neonates.[3] A study done by showed that very hot and humid days due to CC generated large infant mortality effects with increase 
of neonatal mortality by 0.7 deaths per thousand births in developing world.[4]

About $22 \%$ of disease burden, expressed in Disability-Adjusted Life Years (DALYs), is caused by $\mathrm{CC}$ and its negative consequences [4]. It is also estimated that $\mathrm{CC}$ causes nine million premature deaths worldwide, with a projected increase to 12.6 million deaths $(23 \%$ of all deaths $)$ including neonates.[3]

According to the United Nations Office for Disaster Risk \& Centre for Research on the Epidemiology of Disasters, extreme temperatures from CC caused $27 \%$ of all neonatal deaths globally between 1995 and 2015.[5] Hence, the WHO has indicated an additional 250,000annual neonatal deaths are likely to occur in developing countries between 2030 and 2050.[6] The World health organization argues that despite there is improvement in reduction of neonatal morbidity and mortality worldwide, efforts to meet the goal of $75 \%$ reduction failed because of $\mathrm{CC}$ consequences on neonate 'health. $[7,8]$

Studies in Africa are already documenting the problem of high temperatures. Studies conducted in Kenya and Ghana found a correlation between high ambient temperatures and increased all-cause mortality among under-five children.[9] A study conducted in 19 African countries, including Rwanda, found a relationship between high ambient temperatures and increased preterm delivery and lower birth weight.[11] Furthermore, the health burden is expected to double by 2030,[11] and temperatures in Sub Saharan Africa (SSA) are likely to be five-fold hotter than today, mostly affecting under-five children including neonates.[12]

In Rwanda, the effects of CC have affected the country heavily. The recent climate change reports show that since 1970 until 2019, Rwanda has experienced an average temperature increase of $1.4^{\circ} \mathrm{C}$, which is higher than the global average of $0.88^{\circ} \mathrm{C}$.[14] Furthermore, a potential increase to $2.5^{\circ} \mathrm{C}$ by 2030 is considered among the high-risk nations including Rwanda in terms of $\mathrm{CC}$ health risk exposure such as neonatal morbidity and mortality.[13] In Rwanda, more than 50\% of premature deaths due to pneumonia among children under five years [14] and $28 \%$ of neonatal deaths are attributed to CC.[15]

The adverse health effects from climate change demand action from the nursing profession .[17] To help achieve CC related health mitigation and adaptation, the International Council of Nurses (ICN) and International Confederation of Midwives (ICM) have issued the position statements calling nurses and midwives to get involved in climate action activities.[19] In addition to that, the ICN and ICM urge nursing and midwifery professional association members to disseminate information on negative consequences of $\mathrm{CC}$ on health and possible preventive measures to communities.[16]

Various studies have explored nurses' knowledge and attitudes on the potential impact of climate change on human's health. Studies conducted in Ethiopia, Bangladesh, and China have shown that the majority of nurses did not know $\mathrm{CC}$ action was a nursing concern or that their work could influence the development of CC's related health effects.[17] In Rwanda, little is a known and available regarding nurse 'and midwives' awareness and perceptions of CC related health hazards, particularly related to the neonate. Thus, this study assessed nurses' and midwives' awareness level on CC and their perceptions of potential neonatal health risks.

\section{METHODS}

\section{Design}

A descriptive cross-sectional design was used to assess nurses' and midwives' awareness and perceptions of potential neonatal health risks associated with climate change. Data were gathered in four hospitals, including Rwanda Military Hospital, Muhima District Hospital, King Faysal Hospital, and Kigali University Teaching Hospital (CHUK), located in Kigali, Rwanda. These hospitals were selected as they receive the majority of sick neonates transferred from other regions due to their well-equipped neonatology department, including specialized midwives and nurses. The study was conducted between March 05 and May 31, 2019.

\section{Participants' recruitment}

A total of 340 nurses and midwives working in the maternity, pediatrics, and neonatology at the four hospitals made up the sampling frame, of which 184 made up the sample size that was obtained after using the Taro Yamane 'sample size calculation formula, [22]. In the current study, the researcher assumed that the maximum proportion of nurses and midwives who will respond correctly is $(p=0.05)$ with a $95 \%$ confidence. interval and 5\% marginal error.

$$
n=\frac{N}{1+N(e)^{2}}
$$

From this formula: $\mathrm{n}=$ corrected sample size, $\mathrm{N}=$ population size, and $\mathrm{e}=$ Margin of error $(\mathrm{MoE})$. Therefore, $n=340: 1+340(0.05) 2=184$. 
For this study, participants were selected using the simple random sampling technique and by randomly picking 16 staff names written on small folded papers at least 16 persons from each above mentioned department were obtained. The department nursing staff list was obtained from each department in charge at every hospital. The replacement of participants who were absent or missed was done by taking the next person untaken during the lottery.

\section{Measures}

The study used a self-administered questionnaire given to participants. Variables on the questionnaire were in three sections including socio-demographic characteristics, awareness of CC, participants' perceptions of potential neonatal health risks associated with $\mathrm{C}$. The section one included sociodemographic characteristics of participants with 6 items including age, gender, education level, profession, working experience and working department.

The section two consisted of 11 questions on awareness of CC and global warming, current CC situation in Rwanda, causes / risk factors leading to $\mathrm{CC}$ and global warming, risk of CC to human health, Potential neonatal health risks potential measures of CC mitigation and CC adaptation, Personal and professional role and responsibilities in $\mathrm{CC}$ mitigation and $\mathrm{CC}$ adaptation and specific neonatal health associated with CC. All items were scored by responding to "Yes" with 1 point or "No" with 0 points, using the Akrofi and $A l$. method. [20] The response rate to each item was presented in percentage, then after by using Akrofi, Antwi, and Gumbo method[20] participants were classified into four levels of awareness depending on their scores: Very low (<3), Low (3.1-5.4), Moderate (5.5-8.25), and High (8.26-11). Those classes were obtained after all of the 11 items of awareness were scored with 0 point for "No" and 1 point for "Yes" answer for each individual participants. The maximum score was 11 and minimum was 3 . Also the section included questions on the source of CC awareness. The awareness sources that were listed included school, co-workers/Friends, Radio/TV, Social media /internet, journal/ books readings and Workshop/conference. The response was "Yes" or "No" (7 items). (Figure 2 and 3).

The section three included questions about participants' perceptions of potential neonatal health risks associated with CC (9 items) including: prematurity, lower birth weight, sudden death, infections, congenital malformations, respiratory diseases, UV exposure effects, poor post-natal growth disorders and behavioral and psychological disorders. In that section, responses were based on five-point Likert scale and coded from 1 to 5(strongly disagree $=1$, disagree $=2$, unaware $=3$, agree $=4$, and strongly agree $=5$. The item percentages were measured using the frequency. To classify participants' perception class, the total score for nine items was calculated. The maximum score was 5 points and minimum of 1 at each item. Then to find participants' perception class allocation, using Akrofi et Al. method [20] method the cut-off point was calculated with the Receiver Operator Characteristic (ROC) curve in SPSS. The obtained cut off point of 25.5 was found. Two classes were obtained. Low class perception was that of below the cut off point and high class perception was that of above. In the current study, having high perception meant that the participant was able to connect CC to the neonate health risks e.g. Ultra-violet rays affecting the neonate's skin. Then, having low perception meant that the participant does not see a connection between climate change and neonate health risks.

\section{Data collection procedures}

The managers of the three departments (neonatology, maternity, and pediatrics) at the four hospitals were contacted to discuss a convenient time to meet the staff. Midwives or nurses were met individually during day duty hours at their respective working service and invited to participate voluntarily in the study. The selfadministered questionnaire (SAQ) was then given. Completion of the questionnaire took about 20 minutes, and during that time, the investigator stayed near to clarify as needed.

\section{Data analysis}

Descriptive and inferential statistics were used. Socio-demographic data were summarized using descriptive statistics (frequencies and percentages) and the Chi-square and the Spearman correlation tests were used for inferential statistics to assess the relationship between study variables. A p-value of $<0.05$ was considered to be statistically significant

\section{Ethical considerations}

Ethical approval was obtained from the University of Rwanda Institutional Review Board (IRB) under Ref: CMHS/IRB/030/2019. Then, the permission to collect data was also obtained from the research committees or administration of each study hospital. Before data collection, participants signed voluntarily the informed consent form. Confidentiality and anonymity were assured to participants through using only codes and not full names on the questionnaire 


\section{RESULTS}

This study aimed to assess nurses' and midwives' awareness of $\mathrm{CC}$ and perceptions of potential neonatal health risks at selected hospitals in Kigali, Rwanda. The response rate was high because out of the 184 nurses and midwives sampled, 177(95.67\%)

\section{Sociodemographic characteristics of participants}

Table 1: Sociodemographic characteristics of participants

\begin{tabular}{ll}
\hline Characteristics & n (\%) \\
\hline Age (Years) & $70(39.5)$ \\
$30-39$ & $64(36.2)$ \\
$40-49$ & $6(3.4)$ \\
$\geq 50$ & $67(37.9)$ \\
Gender & $110(62.1)$ \\
Male & \\
Female & $98(55.4)$ \\
Education level & $61(34.5)$ \\
Advanced diploma(A1) & $18(10.2)$ \\
Bachelor's & $107(60.5)$ \\
Master's & $68(38.4)$ \\
Profession & $2(1.1)$ \\
Nurse & \\
Midwife & $57(32.2)$ \\
Nurse-Midwife & $63(35.6)$ \\
Working department & $57(32.2)$ \\
Maternity & \\
Neonatology & $30(20.9)$ \\
Pediatrics & $96(54.2)$ \\
Work experience (years) & $44(24.9)$ \\
$<2$ &
\end{tabular}

Table 1 presents the sociodemographic characteristics of the participants. The participation of females was higher $(62.1 \%)$ than males (37.9\%). Most were aged between 30-39 years $(39.5 \%)$, followed by those $40-49$ (36.2\%). Most (55.4\%) had advanced diploma level, and only 10\% had masters' degree. The majority (60.5\%) were nurses, compared to $38.4 \%$ of midwives. Most (35.6\%) were working in the neonatology department while about a third $(35.6 \%)$ and $(32.2 \%)$ were working in maternity and pediatrics, respectfully. completed the questionnaire including 50 at Rwanda Military Hospital, 35 for Muhima District CHUK) and only $2(1.1 \%)$ refused to participate. In contrast, $2.7 \%$ did not submit the questionnaire. Hospital, 41 for King Faysal Hospital, and 51 at 


\section{Climate change awareness among nurses and midwives}

Table 2. Nurses' and midwives' awareness of climate change

\begin{tabular}{lll}
\hline Awareness of climate change (CC) & Yes & No \\
\hline & $\mathbf{n ~ ( \% )}$ & $\mathbf{n ~ ( \% ) ~}$ \\
Climate change and global warming & $88(49.7)$ & $89(50.3)$ \\
Current CC situation in Rwanda & $68(38.4)$ & $109(61.6)$ \\
Causes / risk factors leading to CC and global warming & $63(35.6)$ & $114(64.4)$ \\
Risk to adult health & $54(30.5)$ & $123(69.5)$ \\
Risk specific to neonatal health & $47(26.6)$ & $130(73.4)$ \\
Potential neonatal health risks associated with CC & $44(24.9)$ & $133(75.1)$ \\
Potential measures of mitigation and adaptation to CC & $43(24.3)$ & $134(75.7)$ \\
Role and responsibilities to CC mitigation & $29(16.4)$ & $147(83.6)$ \\
Mainstreaming CC Adaptation \& Mitigation guidelines & $2(1.1)$ & $175(98.9)$ \\
WWHEN Checklist for CCMA at health facility level & $3(1.7)$ & $174(98.3)$ \\
ICN urges to nurses regarding CCMA & $4(2.3)$ & $173(97.7)$ \\
\hline
\end{tabular}

Notes: WWHEN: Waste- Water- Hygiene- Energy- Nutrition. CCMA: Climate change mitigation and adaptation. ICN: International Council for Nurses

Table 2 shows that the majority (50.3\%) were not aware of $\mathrm{CC}$ and global warming, and $64.4 \%$ were not aware of potential causes / risk factors. Those not aware of CC are a threat and risk to adult and neonatal were 69.5, and $73.7 \%$ respectively. Also, the majority $(75.7 \%)$ were not aware of potential measures to be done in mitigation and adaptation to neonatal health risks associated with CC. Then, $83.6 \%$ were not aware of personal and professional role and responsibilities to CC mitigation. Only $1.1 \%$ was aware of the guidelines for mainstreaming $\mathrm{CC}$ adaptation and mitigation in the Health Sector established by the government of Rwanda since 2013, and only $1.7 \%$ were aware of the "WWHEN checklist" for CC mitigation and adaptation at health facility level established by the government of Rwanda since 2013 . Then, a limited proportion $(2.3 \%)$ was aware that ICN had recommended CC mitigation and adaptation.

\section{Climate change awareness level among nurses and midwives}

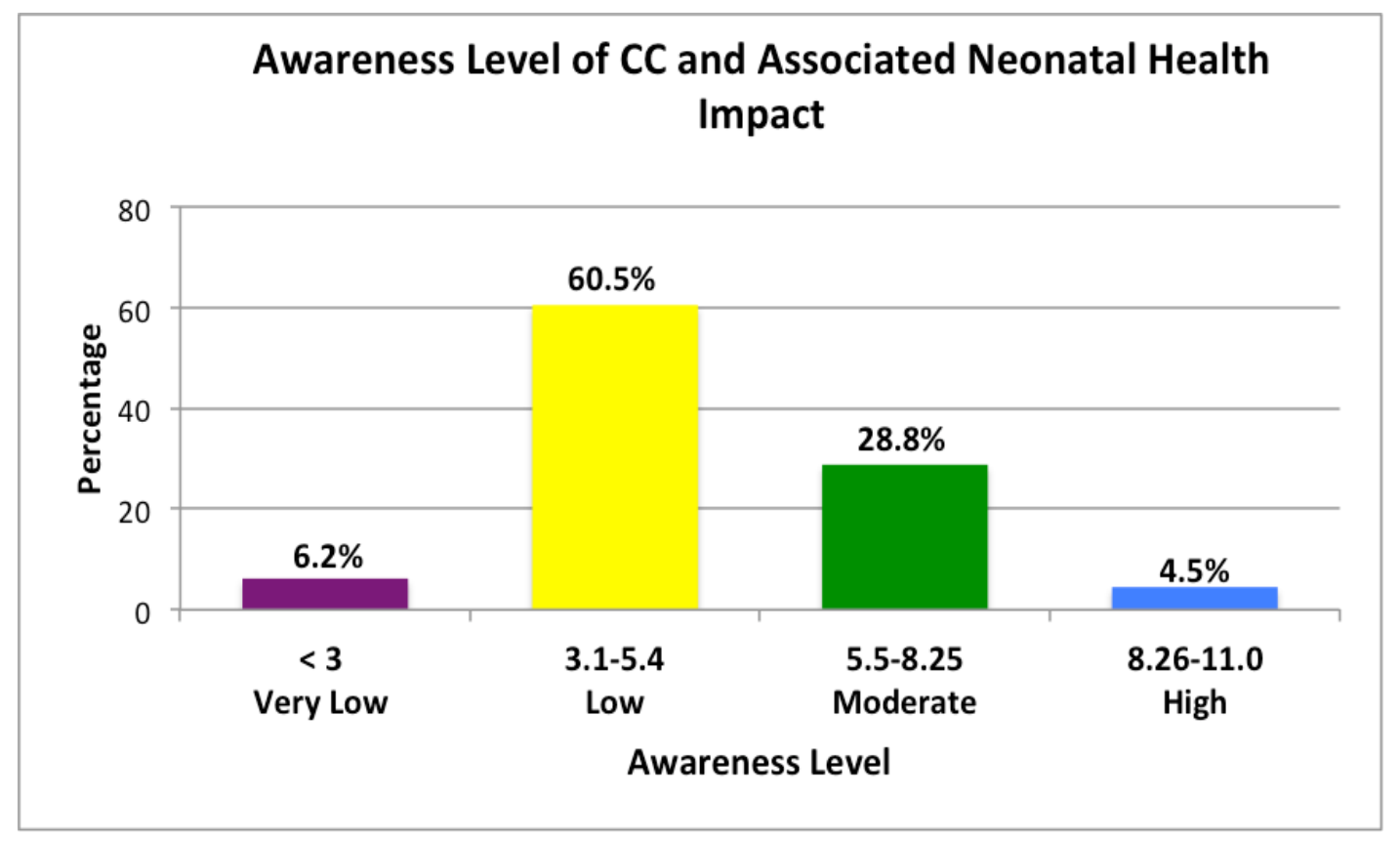

\section{Figure 1. Nurses and Midwives CC Awareness Level}

The nurses' and midwives' CC awareness level is described in Figure 1. After all of the 11 items of awareness were scored with 0 point for "No" and 1point for "Yes" answer for each individual participants, majority 
category107 (60.4\%) was in the low awareness, class with the total score ranging from 3.1 to 5.4 out of $11,6.2 \%$ were found to be in very low-class, $28.8 \%$ in mild class and only $4.5 \%$ scored between 8.26 to 11 out of 11 were classified in high-level awareness.

\section{Climate change awareness source among nurses and midwives}

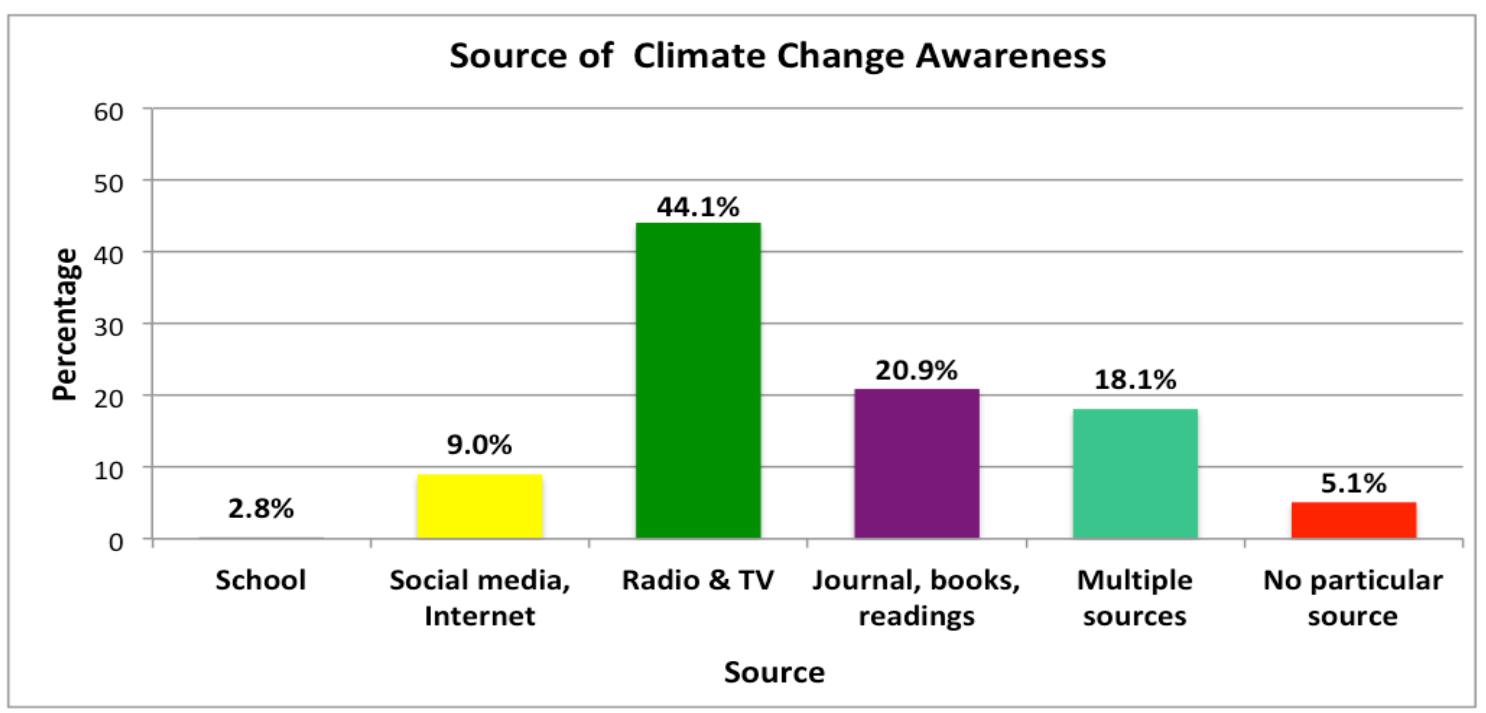

\section{Figure 2. Climate change awareness source}

The Figure 2 shows that the majority (44.1\%) obtained their awareness of CC from radios and TV. However, a limited proportion $(2.8 \%)$ reported obtaining awareness from nursing school.

\section{Comparison between $\mathrm{CC}$ awareness source and awareness level among nurses and midwives}

Nurses and midwives' awareness level on climate change vs awareness source

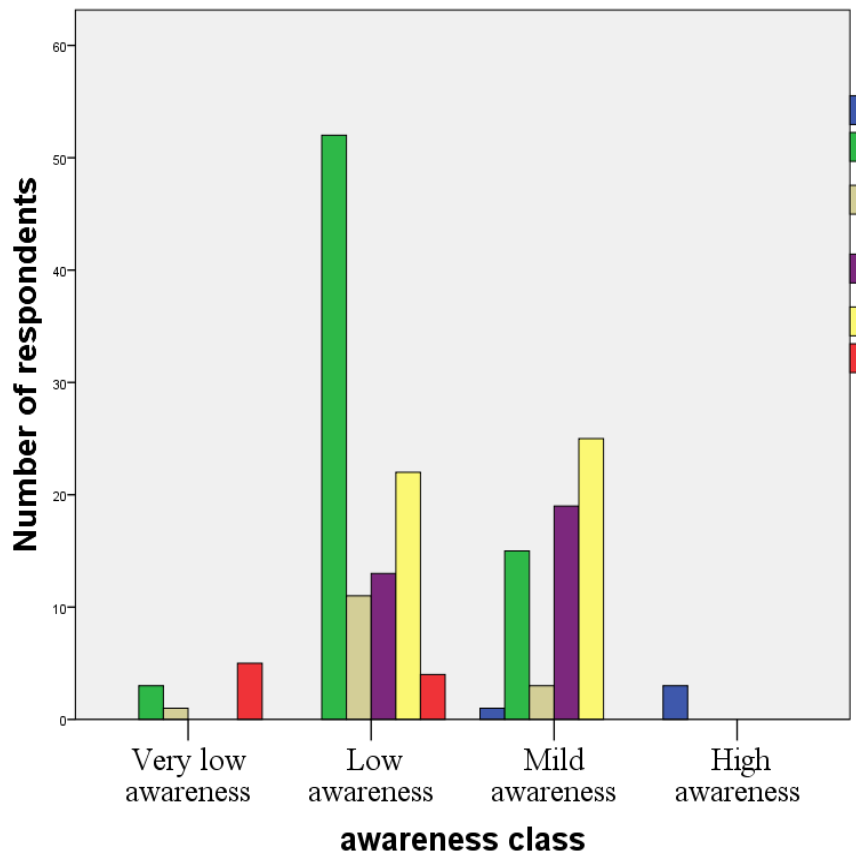

SOURCE OF

AWARENESS

School

Radio/TV

$\checkmark$ Social media

/internet.

Journal/ books

readings

$>1$ source

No any source

Figure 3. Awareness level of CC compared to source 
Figure 3 shows that all participants with high awareness were those who obtained the awareness from school, whereas those with low awareness obtained their information from radio and television

Participants' perceptions of potential neonatal health risks associated with CC

Table 3. Proportion on perceptions of potential neonatal health risks associated with CC

\begin{tabular}{lccccc}
\hline $\begin{array}{l}\text { Potential Neonatal } \\
\text { Health Risks }\end{array}$ & $\begin{array}{c}\text { Strongly } \\
\text { Disagree n }\end{array}$ & $\begin{array}{c}\text { Disagree } \\
\mathbf{n ~ ( \% )}\end{array}$ & $\begin{array}{c}\text { Neutral } \\
\mathbf{n ~ ( \% )}\end{array}$ & $\begin{array}{c}\text { Agree } \\
\mathbf{n}(\%)\end{array}$ & $\begin{array}{l}\text { Strongly } \\
\text { Agree }\end{array}$ \\
\hline Prematurity & $7(4.0)$ & $5(2.8)$ & $81(45.8)$ & $69(39.0)$ & $15(8.5)$ \\
Lower birth weight & $5(2.8)$ & $15(8.5)$ & $89(50.3)$ & $54(30.5)$ & $14(7.9)$ \\
Neonatal sudden death & $3(1.7)$ & $5(2.8)$ & $87(49.2)$ & $70(39.5)$ & $12(6.8)$ \\
Neonatal infections & $8(4.5)$ & $8(4.5)$ & $88(49.7)$ & $68(38.4)$ & $5(2.8)$ \\
Congenital malformations & $8(4.5)$ & $6(3.4)$ & $101(57.1)$ & $58(32.8)$ & $4(2.3)$ \\
Respiratory diseases & $4(2.3)$ & $7(4.0)$ & $85(48.0)$ & $72(40.7)$ & $9(5.1)$ \\
Effects of heat UV exposure & $5(2.8)$ & $3(1.7)$ & $71(40.1)$ & $88(49.7)$ & $10(5.6)$ \\
Poor post-natal growth & $8(4.5)$ & $9(5.1)$ & $83(46.9)$ & $67(37.9)$ & $10(5.6)$ \\
Psychological and behavioral $8(4.5)$ & $10(5.6)$ & $94(53.1)$ & $60(33.9)$ & $5(2.8)$ \\
disorders & & & & &
\end{tabular}

disorders

*Note:UV: ultraviolet rays effects =skin disorders

Table 3 shows that the majority were neutral on their perceptions towards CC associated with prematurity $(45.8 \%)$, lower birth weight $(50.3 \%)$, neonatal sudden death $(49.2 \%)$, neonatal infections $(49.7 \%)$, congenital malformations $(57.1 \%)$, respiratory diseases $(48 \%)$, UV exposure effects $(40.1 \%)$, and poor post-natal growth $(46.9 \%)$.

Participants' classification on perception of potential $\mathrm{CC}$ associated neonatal health risks among nurses and midwives

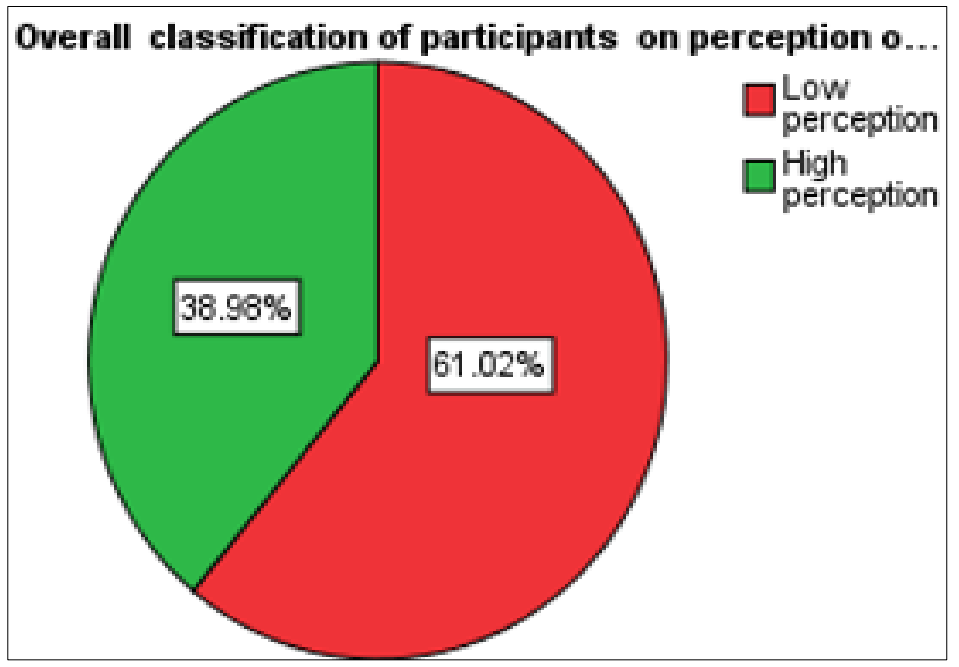

*Note: High perception means above 25.5 cut off point and Low perception means below 25.5 cut off point

Figure 4. Midwives and nurses perceptions of potential neonatal health risks

Figure 4 shows that majority (61.02\%) of participants were in low class perception regarding CC and potential neonatal health risks based on cut-off point of 25.5 obtained from Receiver Operator Characteristic (ROC) Curve. High perception level participants were $38.98 \%$. 
Table 4. Association between $\mathrm{CC}$ awareness level and sociodemographic variables

\begin{tabular}{|c|c|c|c|c|c|c|c|}
\hline \multirow{3}{*}{$\begin{array}{l}\text { Socio-demographic } \\
\text { characteristics }\end{array}$} & \multicolumn{7}{|c|}{ Awareness Level } \\
\hline & Very low & Low & Moderate & High & \multirow[t]{2}{*}{$\mathbf{X}^{2}$} & \multirow[t]{2}{*}{ df } & \multirow[t]{2}{*}{$\begin{array}{l}\text { p- } \\
\text { value }\end{array}$} \\
\hline & $\begin{array}{l}\text { Cut off } \\
\text { point }<3\end{array}$ & $\begin{array}{ll}\text { Cut } & \text { off } \\
\text { point } & 3- \\
5.1 & \\
\end{array}$ & $\begin{array}{lr}\text { Cut } & \text { off } \\
\text { point } & 5.5- \\
8.25 & \\
\end{array}$ & $\begin{array}{l}\text { Cut } \begin{array}{l}\text { off } \\
\text { point } \\
5.6- \\
11\end{array} \\
\end{array}$ & & & \\
\hline Age (years) & & & & & 11.1 & 9 & 0.269 \\
\hline $20-29$ & $3(1.7)$ & $24(13.6)$ & $10(5.6)$ & $0(0.0)$ & & & \\
\hline $30-39$ & $4(2.3)$ & $35(19.8)$ & 31 (17.5) & $0(0.0)$ & & & \\
\hline $40-49$ & $1(0.6)$ & $40(22.6)$ & 21 (11.9) & $2(1.1)$ & & & \\
\hline$\geq 50$ & $1(0.6)$ & $3(1.7)$ & $2(1.1)$ & $0(0.0)$ & & & \\
\hline Gender & & & & & 4.24 & 3 & 0.236 \\
\hline Male & $1(0.6)$ & $40(22.6)$ & $26(14.7)$ & $0(0.0)$ & & & \\
\hline Female & $8(4.5)$ & $62(35.0)$ & $38(21.5)$ & $2(1.1)$ & & & \\
\hline Education & & & & & 14.64 & 6 & 0.023 \\
\hline Advanced diploma & $8(4.5)$ & $62(35.0)$ & $28(15.8)$ & $0(0.0)$ & & & \\
\hline Bachelor's & $2(1.2)$ & $29(16.4)$ & $30(16.9)$ & $1(0.6)$ & & & \\
\hline Master's & $0(0.0)$ & $11(6.2)$ & $6(3.4)$ & 3 (1.9) & & & \\
\hline Profession & & & & & 44.4 & 6 & 0.000 \\
\hline Nurse & $6(3.4)$ & $63(35.6)$ & 37 (20.9) & $3(1.8)$ & & & \\
\hline Midwife & $3(1.7)$ & $38(21.5)$ & $27(15.3)$ & $0(0.0)$ & & & \\
\hline Nurse-Midwife & $0(0.0)$ & $1(0.6)$ & $0(0.0)$ & $1(0.6)$ & & & \\
\hline Department & & & & & 8.48 & 6 & 0.205 \\
\hline Maternity & $1(0.6)$ & $36(20.3)$ & $20(11.3)$ & $0(0.0)$ & & & \\
\hline Neonatology & $6(3.4)$ & $34(19.2)$ & $21(11.9)$ & $2(1.1)$ & & & \\
\hline Pediatrics & $2(1.1)$ & $32(18.1)$ & $23(13.0)$ & $0(0.0)$ & & & \\
\hline Experience & & & & & 11.8 & 9 & 0.225 \\
\hline$<3$ months & $0(0.0)$ & $9(5.1)$ & $4(2.3)$ & $0(0.0)$ & & & \\
\hline $3-12$ months & 1 (0.6) & $13(7.3)$ & $10(5.6)$ & $0(0.0)$ & & & \\
\hline $2-5$ years & $8(4.5)$ & $55(31.1)$ & 33 (18.6) & $0(0.0)$ & & & \\
\hline$>5$ years & $0(0.0)$ & $25(14.1)$ & 17 (9.6) & $2(1.1)$ & & & \\
\hline Hospital & & & & & 12.7 & 9 & 0.175 \\
\hline CHUK & 1 (0.6) & 31 (17.5) & $18(10.2)$ & $0(0.0)$ & & & \\
\hline $\mathrm{RMH}$ & $6(3.4)$ & 21 (11.9) & $22(12.4)$ & $2(1.2)$ & & & \\
\hline $\mathrm{MDH}$ & 7 (4.0) & 21 (11.9) & $22(12.4)$ & $0(0.0)$ & & & \\
\hline $\mathrm{KFH}$ & $1(0.6)$ & $26(14.7)$ & $14(7.9)$ & $2(1.2)$ & & & \\
\hline
\end{tabular}

CHUK Kigali University Teaching Hospital; RMH Rwanda Military Hospital; MDH Muhima District Hospital; King Faisal Hospital.

Table 4 shows there are no statistical significance between age, gender, working experience, level of working hospital, and awareness on CC. However, association is found on levels of education $\left(X^{2}=14.64, d f=6, p=<0.05\right)$, and profession $\left(\mathrm{X}^{2}=44.4, \mathrm{df}=6, \mathrm{p}=<0.05\right)$. There were two significant associations with increased awareness of $\mathrm{CC}$ and its risks on neonatal health; having a master's degree $(\mathrm{p}=0.023)$, and being a nurse $(\mathrm{p}=0.000)$. 


\section{DISCUSSION}

This study aimed to assess nurses' and midwives' awareness of $\mathrm{CC}$ and perceptions of potential neonatal health risks associated with $\mathrm{CC}$ at selected hospitals in Rwanda. In addition, the relationship between socio-demographic characteristics and awareness level on climate change was explored.

\section{Socio-demographic participants}

\section{characteristics of}

The majority $(60.4 \%)$ of participants were young adults and female (62.1\%), which was not surprising because nursing was originally a female dominant profession as argued by (24). There were more nurses $(60.5 \%)$ than midwives, and this finding can be related to the shortage of midwives in Rwanda, and most are appointed to the maternity service. More than half of participants were educated at advanced diploma level (55.4\%) and had $2-5$ years of work experience $(54.2 \%)$. This may be related to that the lowest education level in Rwanda in nursing and midwifery is advanced diploma. Most participants worked in neonatology (35.6\%), compared to maternity $(32.2 \%)$ and pediatrics (32.2\%). The Rwanda Military Hospital (28.8\%) and university teaching referral hospital $(28.2 \%)$ had the highest proportion of participants, while the private $(23.2 \%)$ and district hospital $(19.8 \%)$ had less. Closely similar findings were observed in the study done in Ethiopia [20]

\section{Association between awareness of $\mathrm{CC}$ and socio- demographic variables}

Gender: Women had a higher proportion $(1.7 \%)$ of $\mathrm{CC}$ awareness than men $(0.6 \%)$, though there was no statistical association. Similarly, a study conducted in Ethiopia found that women had a better understanding of the impact of CC than men, [25] and a review by Pearse [22] concluded that women are more likely to recognize $\mathrm{CC}$ as a severe threat. These gender differences may be attributed to the relatively higher social responsibility of Rwandan women to care for their children in their communities, more than males, women are typically the primary caregivers of babies.[27] Therefore, the pattern of female awareness in this study can be a chance to profit when we want to activate the participation of women in debates on mitigation and adaptation to neonatal health risks associated with climate change.

Age: This study shows that participants with a higher level of CC awareness and related neonatal health risks are increased with older age and longer work experience. These findings are similar to studies conducted in Ethiopia [19] and Nigeria. [23] Older people have had more life experiences, e.g., witnessed rising temperatures, and therefore more likely to know the consequences on human health, compared to young ones who have only read about it from books or the internet. Hence, older age HCPs could be at an advantage to support others with CC mitigation and adaption.

Level of education and profession: Participants with a bachelor's or master's degree were more likely to have a higher level of awareness on CC and associated neonatal health risks than those with an advanced diploma. These findings are similar to a study conducted in Bangladesh [21] and China. [30] Highly educated nurses and midwives can and should be taken as a cornerstone in raising CC awareness of neonatal health-related risks and help to shape the attitudes and practices of the new generations toward actions to mitigation and adaptation.

Working hospital: Participants working at CHUK and other referral hospitals were more likely to have a higher level of CC awareness and associated neonatal health risks than those working in private and district hospitals, similar to a study conducted in Bangladesh. [29] University teaching hospitals and referral hospitals are likely to have high-level specialists who are willing to share their knowledge and skills through various lectures, in-service training, and workshops.

Working department: Participants working in the neonatology unit were more likely to have a higher level of CC and associated neonatal health risks, similar to the study conducted in China. [30] Perhaps nurses and midwives deal more with clients who have limited information on the causes of disease and therefore obliged to do deep critical thinking of possible factors related to neonatal morbidity and mortality. Moreover, HCPs in the neonatology service consider environmental factors in treating and preventing relevant disease conditions. We can use them to advocate social and environmental actions for improving neonatal health.

Profession: Nurses were more likely to have a highlevel of CC awareness and associated neonatal health risks than midwives, similar to a study in China where nurses' high CC awareness was the same as their medical and other HCPs counterparts. [30] Perhaps this is related to the differences in educational programs or professional functions between nurses and midwives. Nevertheless, CC should be integrated into nursing and midwifery curricula. 


\section{Climate change awareness among nurses and midwives}

Our results showed that the great number of nurses and midwives had low level awareness regarding climate change. Our findings differ from those of a study done in China [30] where findings showed that the majority of nurses $(76 \%)$ knew about the climate change and its negative effect on human's health. However, our findings are similar to those conducted in Bangladesh where the majority of nurses have low level awareness of $\mathrm{CC}$ and its associated human's health risks. [21] In contrast, a study conducted in Ethiopia found that $77.5 \%$ of health care providers including nurses and midwives had a high level of CC awareness on climate change's health related impact.[19] Our findings may be due to sensitization in CC mitigation and adaptation is still low in Rwandan health facilities.

Additionally, despite the ICN and ICM urged nurses and midwives to play tangible role in mitigation and adaptation to the climate change' associated health consequences, our findings show that very few nurses know their role and responsibilities. Our findings are similar to those of a study done by Anaker,[31] that showed the majority of nurses did not know what they were supposed to do towards mitigation and adaptation to climate change 'related health risks. There is a need for increased awareness on nurses' role and responsibilities for the healthcare sector if we want to respond to climate change's health related negative effects and especially on neonates' health.

\section{Source of CC awareness}

The predominant source of $\mathrm{CC}$ awareness identified by participants was the mass media, specifically the radio and TV (44.1\%), and few (only $2.8 \%$ ) reported obtaining $\mathrm{CC}$ awareness at school (Figure 2). Similarly, a study conducted in Bangladesh showed the majority obtained $\mathrm{CC}$ information through the electronic mass media.[21] The nursing school curriculum is the best option to prepare nurses and midwives to effectively address the health impacts of $\mathrm{CC}$ on neonates as the information received through mass communication is not sufficient to prepare health science students.

\section{Perceptions of potential neonatal health risks associated with CC}

Findings of this study revealed that in general, the great number of participants had a low perception on the connection between climate change and neonatal health risks. This finding is similar to a study in China[24] whereby more than a half of participants could not link the climate change with potential related health effects. Findings of the current study show that there is a need to teach and train nurses and midwives about various consequences of $\mathrm{CC}$ on neonatal health. The most perceived climate change associated neonatal health risk by participant was the effects from heat stroke and of ultraviolet rays $(49.7 \%)$. These findings are similar to a study conducted in East Harlem, New York (USA), where about $50.0 \%$ of the local health officials perceived CC impacts to constitute a severe risk to human health due to heat consequences.[32]

\section{Association between awareness of $\mathrm{CC}$ and socio- demographic variables}

The results of this study show that having a high level of education and working in the neonatology department was associated with having a high level of awareness on $\mathrm{CC}$ and related neonatal health risks. Similarly, a study conducted in China [24] and Ethiopia [27] indicated a higher education level and working department were associated with increased CC awareness, especially in vulnerable populations to $\mathrm{CC}$, were more likely to be aware of related health impacts than others. As education is increasing, the level of knowledge and experiences related to environmental issues also increases. It is, therefore, more efficient and effective to introduce CC-related health information in all levels of nursing and midwifery education, even in grade school, for early and sustainable prevention.

\section{Limitations}

This study was conducted in four selected hospitals in Rwanda; therefore, results may vary at other sites. Due to a small sample size, these findings cannot be generalized. Furthermore, data were based on self-report in busy working hours; thus, this may have affected their responses and, therefore, data accuracy. Moreover, the Likert scale used for assessing perceptions may have caused distortion when participants agreed with statements as presented (acquiescence response bias (34)), presented themselves in a positive light (social desirability bias [35], or avoided using strongly disagree or strongly agree with responses (central tendency bias.[36]

\section{Recommendations}

Nurses and midwives working with neonates need the knowledge and skills on CC mitigation and adaptation to reduce neonatal health hazards. Thus, based on our findings, we recommend offering in-service hospital training on $\mathrm{CC}$ and its effect on neonate's health and integrating $\mathrm{CC}$ and health into the nursing and midwifery curricula. Also, we recommend to nursing and midwifery schools in Rwanda to creating opportunity to nurses to upgrade their education in 
environmental health specialties as recommended by the ICN and ICM. In addition, social media and mass communication channels (TV/RADIOs) should be strengthened regarding delivering messages on climate change and related human's health impact. We finally recommend a countrywide study on barriers or factors hindering climate change action among midwives and nurses in Rwanda.

\section{CONCLUSION}

This study revealed a low-level awareness of climate change and low perceptions of potential climate change associated neonatal health risks among nurses and midwives working in the four selected hospitals in Kigali, Rwanda. A higher education level, working in neonatology, and longer working experience were found to be associated with having high level awareness of climate change and high perceptions of potential neonatal health risks associated with climate change. Offering in-service training and integrating $\mathrm{CC}^{\prime}$ health risks in the nursing curricula could motivate climate action among Rwandan nurses and midwives.

\section{Authors' contributions}

RN contributed to the original study, data collection, analysis, and manuscript writing. PM and MR supervised the research study, and PM contributed to the manuscript.

\section{Acknowledgments}

We acknowledge all participants that made this study successful at King Faisal Hospital, CHUK, Rwanda Military Hospital, and Muhima District hospital for their invaluable role in this study.

This article is published open access under the Creative Commons Attribution-NonCommercial NoDerivatives (CC BYNCND4.0). People can copy and redistribute the article only for noncommercial purposes and as long as they give appropriate credit to the authors. They cannot distribute any modified material obtained by remixing, transforming or building upon this article. See https://creativecommons.org/licenses/ by-nc-nd/4.0/

\section{REFERENCES}

1. World Health Organization. Ten threats to global health in 2019. Emergencies. 2019.

2. Gennaro S, O'Connor C, Marx M. Global Health of Babies and Children. MCN The American Journal of Maternal/Child Nursing. 2017.

3. BARD D. Health Consequences of Climate Change. Int J Med Surg. 2017;

4. Geruso M, Spears D. Heat, Humidity, and Infant Mortality in the Developing World. SSRN Electron J. 2018;
5. Pugatch T. Tropical storms and mortality under climate change. World Dev. 2019;

6. UNISDR. 2015 Disasters in Numbers. United Nations Office for Disaster Risk Reduction Publications. 2016.

7. WHO.WHO Call On Countries To Protect Health From Climate Change. Neurosciences (Riyadh, Saudi Arabia). 2016.

8. WHO. WHO | Causes of child mortality. Who. 2018;

9. Philipsborn RP, Chan K. Climate change and global child health. Pediatrics. 2018;

10. Serdeczny O, Adams S, Baarsch F, Coumou D, Robinson A, Hare W, et al. Climate change impacts in Sub-Saharan Africa: from physical changes to their social repercussions. Reg Environ Chang. 2017;

11. Grace K, Davenport F, Hanson H, Funk C, Shukla S. Linking climate change and health outcomes: Examining the relationship between temperature, precipitation and birth weight in Africa. Glob Environ Chang. 2015;

12. Silva RA, West JJ, Lamarque JF, Shindell DT, Collins WJ, Faluvegi G, et al. Future global mortality from changes in air pollution attributable to climate change. Nat Clim Chang. 2017;

13. Weber T, Haensler A, Rechid D, Pfeifer S, Eggert $\mathrm{B}$, Jacob D. Analyzing Regional Climate Change in Africa in a $1.5,2$, and $3^{\circ} \mathrm{C}$ Global Warming World. Earth's Futur. 2018;

14. Gebauer C, Doevenspeck M. Adaptation to climate change and resettlement in Rwanda. Area. 2015;

15. Byers E, Gidden M, Leclere D, Balkovic J, Burek $\mathrm{P}$, Ebi K, et al. Global exposure and vulnerability to multi-sector development and climate change hotspots. Environ Res Lett. 2018;

16. Persson LÅ, Rahman A, Peña R, Perez W, Musafili A, Hoa DP. Child survival revolutions revisited - lessons learned from Bangladesh, Nicaragua, Rwanda and Vietnam. Acta Paediatrica, International Journal of Paediatrics. 2017.

17. Leffers J, Levy RM, Nicholas PK, Sweeney CF. Mandate for the Nursing Profession to Address Climate Change Through Nursing Education. J Nurs Scholarsh. 2017;49(6):679-87.

18. Nicholas PK, Breakey S. Climate Change, Climate Justice, and Environmental Health: 
Implications for the Nursing Profession. J Nurs Scholarsh. 2017;

19. Nicholas PK, Breakey S. Climate Change, Climate Justice, and Environmental Health: Implications for the Nursing Profession. J Nurs Scholarsh. 2017;

20. Angelini K. Climate Change, Health, and the Role of Nurses. Vol. 21, Nursing for Women's Health. 2017. p. 79-83.

21. Xiao J, Fan W, Deng Y, Li S, Yan P. Nurses' knowledge and attitudes regarding potential impacts of climate change on public health in central of China. Int J Nurs Sci. 2016;3(2):15861.

22. Borkowf CB, Johnson LL, Albert PS. Power and Sample Size Calculations. In: Principles and Practice of Clinical Research. 2018.

23. Akrofi M, Antwi S, Gumbo J. Students in Climate Action: A Study of Some Influential Factors and Implications of Knowledge Gaps in Africa. Environments. 2019;

24. Ross D. Challenges for Men in a Female Dominated Environment Challenges for Men in a Female Dominated. Health and Social Care. 2017.

25. Nigatu AS, Asamoah BO, Kloos H. Knowledge and perceptions about the health impact of climate change among health sciences students in Ethiopia: A cross-sectional study. BMC Public Health. 2014;

26. Pearse R. Gender and climate change. Wiley Interdiscip Rev Clim Chang. 2017;

27. Osman A, Gaffer Y, Sharkawy A, Brandon D. Maternal cultural practices for neonates' care in upper Egypt. Women and Birth. 2018;

28. Sola AO, Michael E. Awareness of Climate Change and Sustainable Development among Undergraduates from two Selected Universities in Oyo State, Nigeria. World J Educ. 2016;
29. Kabir MI, Rahman MB, Smith W, Lusha MAF, Azim S, Milton AH. Knowledge and perception about climate change and human health: Findings from a baseline survey among vulnerable communities in Bangladesh. BMC Public Health. 2016;

30. Yang L, Liao W, Liu C, Zhang N, Zhong S, Huang C. Associations between Knowledge of the Causes and Perceived Impacts of Climate Change: A Cross-Sectional Survey of Medical, Public Health and Nursing Students in Universities in China. Int $\mathrm{J}$ Environ Res Public Health. 2018;

31. Anåker A, Nilsson $\mathrm{M}$, Holmner Å, Elf $\mathrm{M}$. Nurses' perceptions of climate and environmental issues: A qualitative study. J Adv Nurs. 2015;

32. Sheffield PE, Durante KT, Rahona E, Zarcadoolas C. Emerging roles of health care providers to mitigate climate change impacts: A perspective from East Harlem, New York. Health Hum Rights. 2014;

33. Bunce AE, Griest S, Howarth LC, Beemsterboer P, Cameron W, Carney PA. Educating youth about health and science using a partnership between an academic medical center and community-based science museum. J Community Health. 2009;

34. Kam CCS, Meyer JP. How Careless Responding and Acquiescence Response Bias Can Influence Construct Dimensionality: The Case of Job Satisfaction. Organ Res Methods. 2015;

35. Latkin CA, Edwards C, Davey-Rothwell MA, Tobin KE. The relationship between social desirability bias and self-reports of health, substance use, and social network factors among urban substance users in Baltimore, Maryland. Addict Behav. 2017;

36. Douven I. A Bayesian perspective on Likert scales and central tendency. Psychon Bull Rev. 2018; 